\title{
Reply: Elevated Intra-Abdominal Pressure is a "Second-Hit"
}

\author{
John M. Scollay • Rowan W. Parks
}

Published online: 17 February 2010

(C) Société Internationale de Chirurgie 2010

We thank Dr. Basu for his interest in our article [1]. Dr. Basu highlights how in critically ill patients intraabdominal hypertension (IAH) could act as a "second-hit" and compromise anastomotic integrity.

The primary aim of our prospective study was to determine the incidence of IAH in patients undergoing major elective abdominal surgery. The majority of these patients made an uncomplicated recovery and would not be regarded as "critically ill."

Within the limitations of this relatively small study, we found no evidence to suggest that intra-abdominal pressure (IAP) should be routinely measured following elective surgery. Clearly, it may be necessary to initiate IAP monitoring in those elective patients who develop postoperative critical illness.

Abdominal compartment syndrome (ACS) is a distinct clinical entity resulting in significant cardiorespiratory deterioration and should be managed by prompt decompressive laparotomy. In contrast, there is no evidence to suggest that IAH has a deleterious effect on postoperative recovery, and there is limited guidance as to how IAH should be managed. Therefore, it would appear to be unnecessary to monitor IAP in all patients undergoing elective upper GI surgery.

However, a recent review article has highlighted how IAH can be managed with nonoperative techniques [2], and it is possible that nonoperative management of IAH and optimization of abdominal perfusion may become part of routine clinical care. Only if it can be demonstrated that this approach improves outcome after elective abdominal surgery would routine measurement of IAP be advocated.

\section{References}

1. Scollay JM, de Beaux I, Parks RW (2009) Prospective study of intra abdominal pressure following major elective abdominal surgery. World J Surg 33:2372-2377

2. Cheatham ML (2009) Nonoperative management of intraabdominal hypertension and abdominal compartment syndrome. World J Surg 33:1116-1122
J. M. Scollay $(\bowtie)$

Department of Surgery, Ninewells Hospital and Medical School,

Dundee, UK

e-mail: john.scollay@nhs.net

R. W. Parks

Department of Clinical and Surgical Sciences (Surgery),

University of Edinburgh, Edinburgh, UK 